\title{
Deep Concealed Coastal Fault of Dagang Area, North China: Geophysical Characteristics from Potential Field Data and its Geological Implications
} $\mathrm{Ya} \mathrm{Xu}^{1 *}$, Tianyao Hao', Qiuliang Duan ${ }^{1}$ and Jiaodong Zhang ${ }^{2}$

${ }^{1}$ Key Laboratory of Petroleum Resources Research, Institute of Geology and Geophysics, Chinese Academy of Sciences, Beijing 100029, China ${ }^{2}$ Chinese Academy of Geological Sciences, Beijing 100037, China

\begin{abstract}
The coastal fault of Dagang is an important tectonic transition zone in the Dagang area, North China. The former speculations of the existence of the coastal fault are mainly from geology studies. In this paper, we investigate the characteristics of Bouguer gravity anomaly and aeromagnetic anomaly, and provide geophysical evidences of the coastal fault. The upward continuation, directional derivative, wavelet analysis and 3D principle component analysis results of the gravity anomaly and reduction to pole magnetic anomaly are used to extract the coastal fault feature. The main indications of the coastal fault can be summarized with three aspects: (1) linear gravity gradient belt; (2) anomaly transition zone and (3) beard shaped magnetic anomalies. All these geophysical characteristics indicate the existence of a fault along the costal of Dagang area. Based on the deep fault system of Dagang area, a geodynamic model is given which shows two tectonic evolution stages with the stress field changed from NS compressive stress field of the Triassic to early-middle Jurassic to the NW-SE extensional stress field of the late Jurassic to Paleogene, and the coastal fault of Dagang also changed from the left-lateral strike-slip to the dextral strike-slip. The coastal fault of Dagang controlled the formation of the Qikou sag with regional deep faults. It also is the main uplifting channel of the magma and is the main control factor of the igneous rocks in this region.
\end{abstract}

Keywords: Deep concealed fault; Gravity; Magnetic; Dagang area

\section{Introduction}

Dagang area is located in the north central part of the Bohai Bay Basin, North China. Figure $1 \mathrm{~b}$ shows the location and the tectonic frame of the Dagang area. For decades, people have speculated that one deep buried fault exists along the coastline of Dagang. The main evidences of the coastal fault are all from geology studies, such as the comparison studies on tectonic styles, strata and igneous rocks distribution, etc. First, the coastline is the contact zone of two different crystalline basements: Luxi basement and Taihang basement (Figure 1a). The main strikes of the Cenozoic sub-tectonic units are different between the two sides of the coastline: NE-NEE direction in western side and EW directionin eastern side. The Cenozoic fault system provides direct indication for the strike direction transition [1]. The Mesozoic strata only exist in the western coastline, and the coastal fault controls the development of the Mesozoic strata [2]. Second, the igneous rocks distribute mostly on the western coast and seldom develop on the eastern coast [2,3]. The distribution of igneous rocks from aeromagnetic data also shows the same character [4]. The seismic exploration results reveal that the deepest Cenozoic sedimentary area is located in the eastern coast, the maximum depth can reach as deep as $10 \mathrm{~km}$; while on the western side, the depth of Cenozoic sedimentation averages $5-7 \mathrm{~km}$. But the seismic exploration results can not reveal the Pre-Cenozoic structures due to the limitation of the exploration ability. The former gravity and magnetic field study of the Bohai Bay basin has proposed the deep fault system: Lankao-Liaocheng-Yanshan-Dawa fault zone [5]. Its location coincides with the costal fault in the Dagang area. It's possible that the coastal fault is one section of this deep fault zone.

The structure of the coastal of Dagang area play an important role for the regional tectonic setting. The discussion of the existent of the coast fault is key to understand the difference of the basement properties and the deep structure. Further, it also benefit to analyze the formation of the sedimentary basin and the control factors from deep structure. Up to now, the costal fault is still not fully recognized, especially from geophysical characteristics. Here we use high resolution gravity and magnetic data to extract the geophysical characteristics which can be used for deep fault analysis and give the indications of the coast fault of Dagang from geophysical view.

\section{Geology and Geophysical Background}

\section{Geology background}

The location of the study area has been shown in Figure 1a, which mainly consists of Cang-dong Uplift, Huanghua Depression, Chengning Uplift and Shaleitian Uplift. The Cenozoic sub-tectonic units in Huanghua Depression are characterized by different colors. In this region, the crystalline basement is mainly of Archean to lowerProterozoic metamorphic rocks. Three types of crystalline basement: Taihang, Luxi and Yanshan basement, can be divided according to magnetic field study [6]. The thickness of the overlying Cenozoic sedimentation can reach 3-10 km in Huanghua Depression.

\section{Geophysical data}

The Bouguer gravity and aeromagnetic data are extracted from the geophysical database of Bohai Bay region, compiled by the Institute of geology and geophysics, CAS [6]. The data were converted to the grid file with sample distances in the $\mathrm{x}$ and $\mathrm{y}$ directions of $1 \mathrm{~km}$ interval.

The characteristics of the Bouguer gravity anomaly (Figure 2) are consistent with the uplift and depression patterns. The Huanghua

*Corresponding author: Ya Xu, Key Laboratory of Petroleum Resources Research, Institute of Geology and Geophysics, Chinese Academy of Sciences, Beijing 100029, China, Tel: 010-82998001; E-mail: xuya@mail.iggcas.ac.cn

Received June 25, 2014; Accepted July 14, 2014; Published July 24, 2014

Citation: Xu Y, Hao T, Duan Q, Zhang J (2014) Deep Concealed Coastal Fault of Dagang Area, North China: Geophysical Characteristics from Potential Field Data and its Geological Implications. J Geophys Remote Sensing 3: 127 doi:10.4172/2169-0049.1000127

Copyright: (c) $2014 \mathrm{Xu} \mathrm{Y,} \mathrm{et} \mathrm{al.} \mathrm{This} \mathrm{is} \mathrm{an} \mathrm{open-access} \mathrm{article} \mathrm{distributed} \mathrm{under}$ the terms of the Creative Commons Attribution License, which permits unrestricted use, distribution, and reproduction in any medium, provided the original author and source are credited. 
Citation: Xu Y, Hao T, Duan Q, Zhang J (2014) Deep Concealed Coastal Fault of Dagang Area, North China: Geophysical Characteristics from Potential Field Data and its Geological Implications. J Geophys Remote Sensing 3: 127. doi:10.4172/2169-0049.1000127

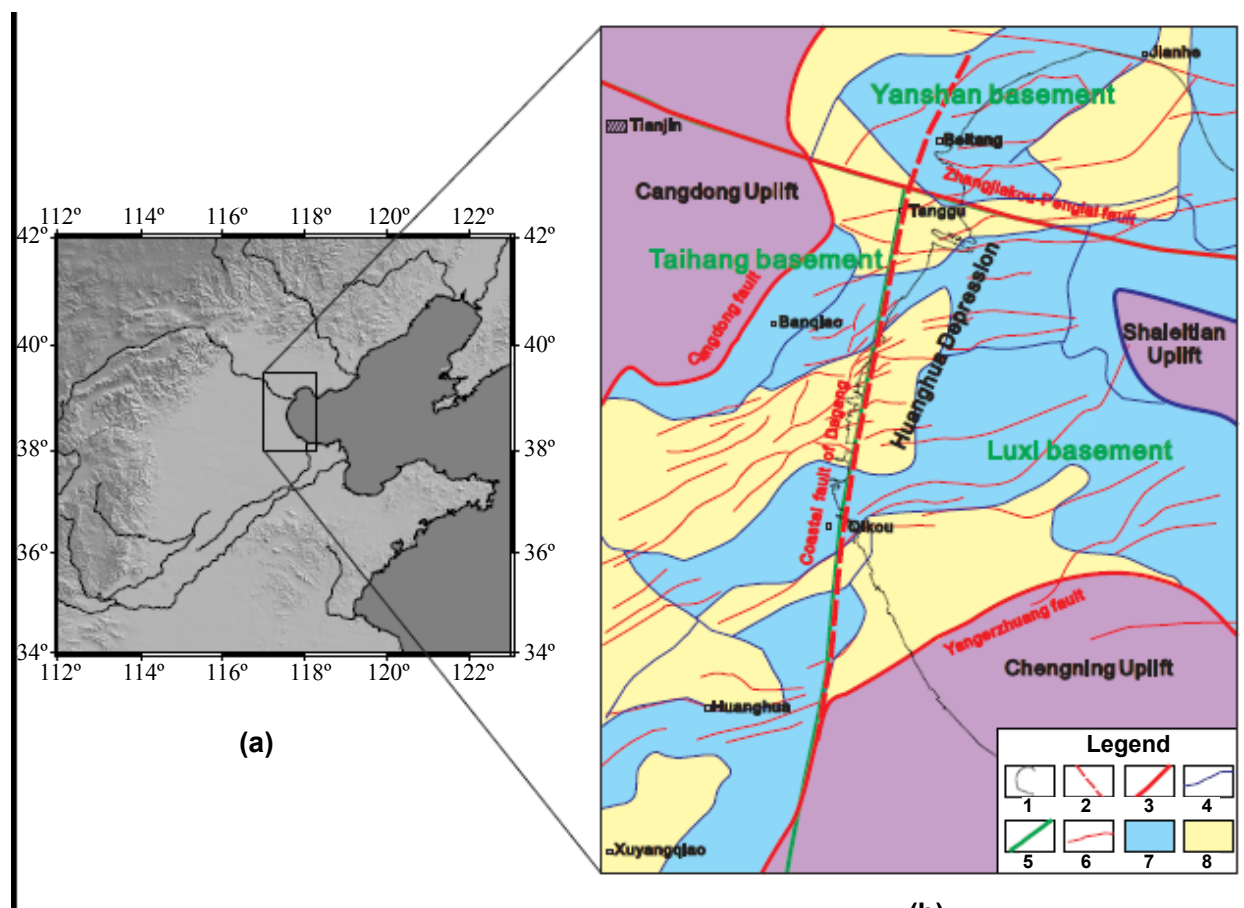

(b)

Figure 1: The location and the tectonic frame map of the Dagang area.

(a) The location of the study area;

(b) The tectonic frame of the study area. Legend stands for: 1-the costal line; 2-the costal fault of Dagang deduced from this study; 3-tectonic boundary and deep faults; 4-subtectonic boundary; 5-boundary of crystalline basements; 6-Cenzoic faults from seismic interpretation; 7-the positive sub-tectonic units in Huanghua Depression (Salients and Buried mount); 8-The negative sub-tectonic units in Huanghua Depression (Sags).

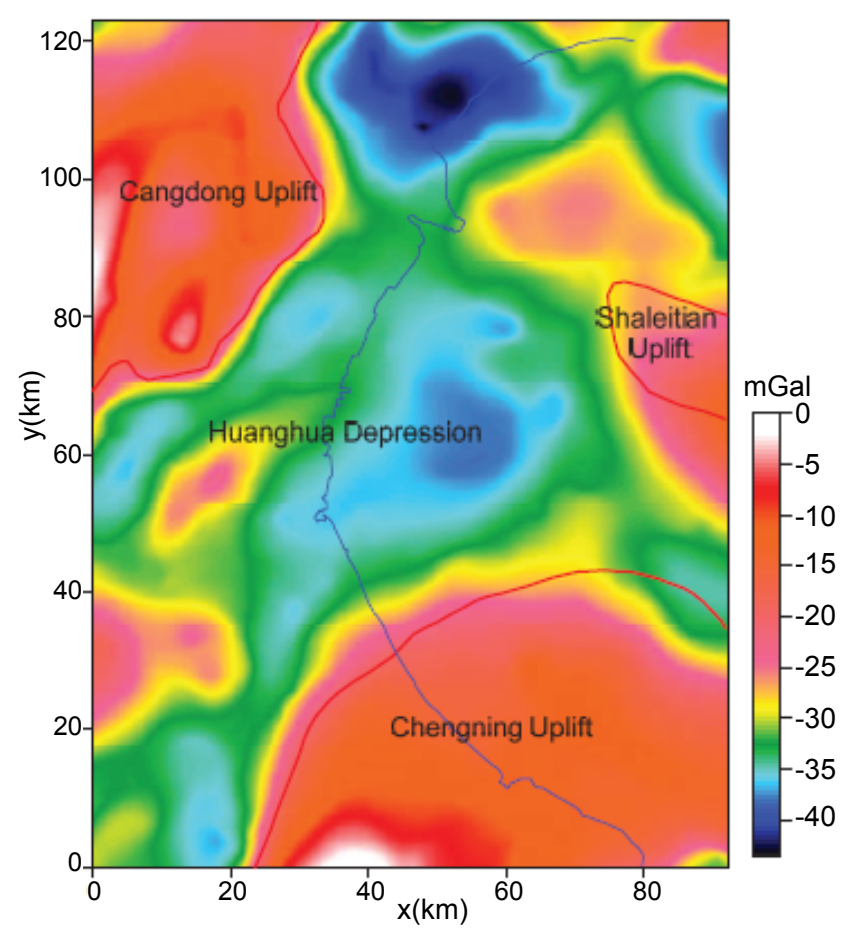

Figure 2: The Bouguer gravity anomaly map of the Dagang area. The black-line indicates the location of the gravity inversion profile.
Depression is a low value gravity anomaly area, surrounded by the highvalue anomalies correspond to uplifts. The local gravity undulations in the Huanghua Depression correspond to smaller sags and salients, forming a superimposed multi-scale gravity anomaly pattern.

The aero-magnetic anomaly data (Figure 3a) divided the Dagang area into three anomaly zones with high anomaly in the north and south-east part and the low value in the middle part. The high magnetic anomaly in north-west and south-east part correspond to the Cangxian uplift and Chengning uplift respectively, and the high anomaly in the north-east part is corresponding to the Beitang sag, which caused mainly by the igneous rocks in this area. The low magnetic anomaly area is mainly in the Qikou sag.

The gravity and magnetic data can clearly react the main tectonic settings of the Dagang area.

\section{Petrophysical property}

The main effect factors of gravity and magnetic anomaly can be attributed to the density contrast and geometry. It's important to learn the density and magnetic susceptibility character for further anomaly analysis caused by the deep buried coastal fault.

The density and magnetic susceptibility characters have been summarized based on the statistic data [6]. There are three main density contrast interfaces: (1) the interface between Paleogene and Neogene with a density contrast about $200-300 \mathrm{~kg} / \mathrm{m}^{3}$; (2) the interface between Paleogene-Cretaceous and Jurassic with a density contrast of $150 \mathrm{~kg} / \mathrm{m}^{3}$ and (3) the Moho discontinuities with a density contrast of $400 \mathrm{~kg} / \mathrm{m}^{3}$. The main magnetic source rocks are mainly from Archean to lower- 
Citation: Xu Y, Hao T, Duan Q, Zhang J (2014) Deep Concealed Coastal Fault of Dagang Area, North China: Geophysical Characteristics from Potential Field Data and its Geological Implications. J Geophys Remote Sensing 3: 127. doi:10.4172/2169-0049.1000127

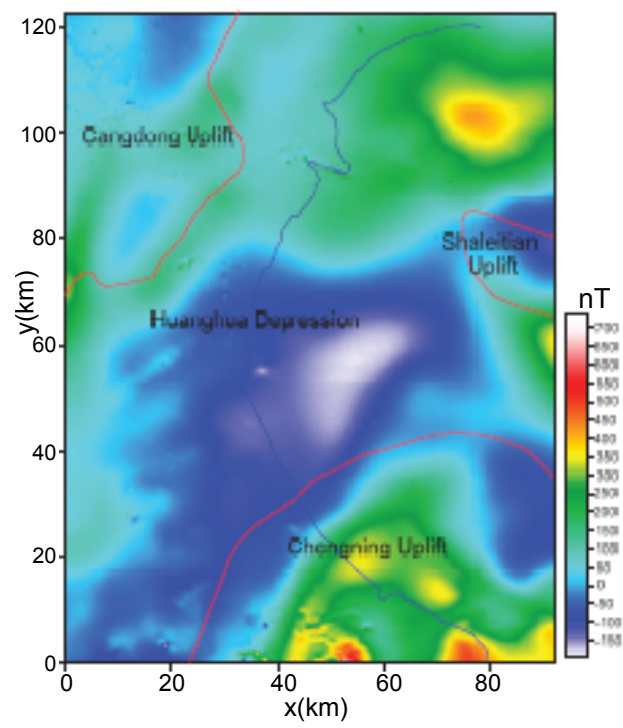

(a)

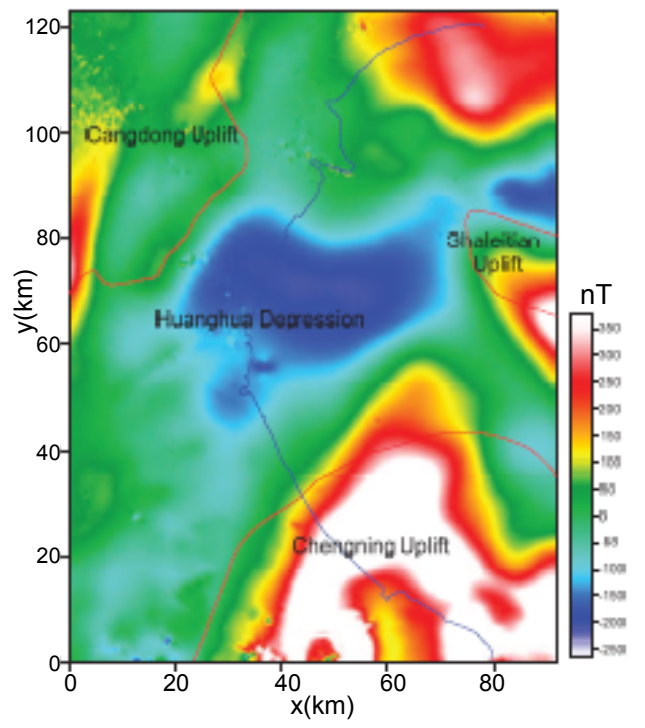

(b)

Figure 3: The reduction to the pole magnetic anomaly map of the Dagang area.

proterozoic crystalline basement and igneous rocks. The magnetic susceptibility of Archean is about $935-4700 \times 10^{-5}$ SI. The magnetic susceptibility of igneous rocks is generally thousands of $10^{-5} \mathrm{SI}$.

These petrophysical property studies indicate the anomaly sources and provide basic parameters for the data processing and gravity inversion.

\section{Methods and Results}

\section{Methods}

The density and magnetic susceptibility contrast of the two sides of the faults is the physical basement for fault detection using gravity and magnetic data. The large and deep fault system can be easily located based on potential field data, especially using magnetic anomaly data when there exist igneous intrusion along the fault. Generally, the gravity and magnetic anomaly characteristics used for fault identification include gradient belts, transform belts, linear belts, string bead-shaped magnetic anomaly etc. For deep concealed fault, its gravity or magnetic anomaly is usually weak due to the anomaly decay with the depth, and its anomaly is usually submerged with the anomalies of shallow geology bodies. To highlight or spate the anomaly of the deep concealed fault, the processing of the gravity and magnetic data is needed. Here, we use some conventional potential data processing methods and some methods based on signal processing to identify the weak anomaly of the deep concealed fault.

Conventional processing: Conventional processing methods usually refer to the continuation, derivation computations of potential field data. Here, based on the spectral analysis of potential field data and the properties of Fourier transform, we adopt the frequency domain to do continuation and derivation. Suppose $f(x ; y)$ is potential field anomaly, and $F\left(k_{x}\right) ;\left(k_{y}\right)$ is its Fourier transform, $k_{x}$ and $k_{y}$ are the corresponding wavenumbers, the conventional processing multiply the $F\left(k_{x}\right) ;\left(k_{\gamma}\right)$ by di_erent frequency transform factors $T\left(k_{x}\right) ;\left(k_{\gamma}\right)$ and get the $F^{\prime}\left(k_{x}\right) ;\left(k_{y}\right)$. Then the inverse Fourier transform of $F^{\prime}\left(k_{x}\right) ;\left(k_{y}\right)$ give corresponding processing results $f(x ; y)$. In order to study the anomaly characteristics of deep seated fault system, the upward continuation and the derivation processing are used in this paper. For the aeromagnetic data, the reduction-to-pole (RTP) was first applied for the original anomaly data and then to be used for the further process. The operators for the upward continuation, derivation and the RTP in Fourier domain can be found in $[7,8]$.

Methods based on derivative processing: Based on the derivation processing, some extensions are proposed for anomaly detection. Compare to the upward continuation, the methods based on derivation are helpful to enhance weak signal and identify the directions anomaly variation on a certain extent.

Assume the $\mathrm{M}$ is the gravity or magnetic anomaly, they are the first order derivative of the anomaly along the $\mathrm{x}, \mathrm{y}$ and $\mathrm{z}$ axis, we can define the extended derivation such as the total horizontal derivative (THDR), the analytical signal modules (ASM) and the tilt angle (TA) [9]. The formula is:

$$
\begin{aligned}
& T H D R=\sqrt{\left(\frac{\partial M}{\partial x}\right)^{2}+\left(\frac{\partial M}{\partial y}\right)^{2}} \\
& A S M=\sqrt{\left(\frac{\partial M}{\partial x}\right)^{2}+\left(\frac{\partial M}{\partial y}\right)^{2}+\left(\frac{\partial M}{\partial z}\right)^{2}} \\
& T A=\arctan \left(\frac{\partial M}{\partial z} / \sqrt{\left(\frac{\partial M}{\partial x}\right)^{2}+\left(\frac{\partial M}{\partial y}\right)^{2}}\right)
\end{aligned}
$$

Wavelet transform: For $f(x) \in L^{2}(R)$ its continuous wavelet transform can be defined as:

$$
W T_{f}(\mathrm{~s}-\tau)=\frac{1}{\sqrt{S}} \int_{-\infty}^{+\infty} f(\chi) \psi *\left(\frac{\chi-\tau}{s}\right) d \chi=<f(\chi), \psi_{s \tau}(\chi)>
$$

$\psi(\chi)$ is the wavelet basis function, ${ }^{\star}$ stands for conjuctive, $\psi_{s \tau}(\chi)=\frac{1}{\sqrt{S}} \psi *\left(\frac{\chi-\tau}{s}\right)$ is the 
Citation: Xu Y, Hao T, Duan Q, Zhang J (2014) Deep Concealed Coastal Fault of Dagang Area, North China: Geophysical Characteristics from Potential Field Data and its Geological Implications. J Geophys Remote Sensing 3: 127. doi:10.4172/2169-0049.1000127

Page 4 of 8

wavelet after shifting and scaling. $\mathrm{S}>0$ is the scale factor, $\tau$ is the shifting. It can be also expressed in frequency domain equally as:

$$
W T_{f}(\mathrm{~s}-\tau)=\frac{\sqrt{s}}{2 \pi} \int_{-\infty}^{+\infty} F(k) \psi(s k) e^{j k \tau} d k
$$

To spate the anomaly of deep geology bodies, we adopt a low-pass and isotropic wavelet basis, Halo wavelet [10], to process the gravity and the RTP magnetic data.

\section{Geophysical processing results}

Generally, gravity and magnetic anomalies are the superposition anomalies induced by all underground geologic bodies. The anomaly caused by faults can be identified directly from the gravity and magnetic anomaly or their processing results. The standard processing techniques can be used to interpret concealed faults [11]. The edge detection methods such as horizontal gradient or total horizontal derivative [12,13], wavelet analysis [14], steerable filters [15], etc. and some data enhancement techniques $[16,17]$ have great help to the fault detection. In this paper, some of the methods are applied to detect the deep concealed costal fault of Dagang.

The coastal fault of Dagang is considered buried in the deep part of the crust. The corresponding anomaly is small because of the depth-attenuation effect of potential field and it's always submerged under other large anomalies. So it's difficult to identify the costal fault anomaly only according to the original anomaly.

Based on the distribution of Pre-Cenozoic strata [6], the Cenozoic sedimentary basement and the crystalline basement have greatly different distribution. And the strata ensemble is different on the two sides of the coastal line. Combined with the density and magnetic susceptibility character, the buried coastal fault can cause certain gravity and magnetic anomaly. Therefore, it's possible to extract some anomaly characters of the coastal fault from the original anomaly.

To separate the deep structural anomaly, the upward continuation, multi-scale wavelet analysis and 3D principal component analysis (PCA) results are rended to analyze the regional anomaly caused by deep structures. The $3^{\text {rd }}-5^{\text {th }}$ order wavelet decomposition results using Halo wavelet [18] and the 3D principle component analysis [19] are used to assist to suppress the anomaly caused by shallow structures. The gradient characters indicate the basic trend of the coastal fault of Dagang.

To further investigate the anomaly character of the costal fault, the standard processing methods includes RTP of magnetic data; upward continuation (at different levels), various directional derivatives, horizontal and vertical gradient etc. are applied for the fault detection. All these processing is done in Fourier domain [8].

To shift the magnetic anomalies to the top of their respective sources, we first do reduction to the pole (RTP) to the aeromagnetic data. It's helpful to find the magnetic sources with correct locations using the RTP magnetic data. The following magnetic processings are all based on the RTP magnetic anomaly. The earth magnetic inclination and declination parameter we used in RTP process are $55^{\circ} \mathrm{C}$ and $-5.6^{\circ} \mathrm{C}$ respectively. The total trends of RTP magmatic anomaly (Figure $3 \mathrm{~b}$ ) reacts the magnetic effects caused by crystal basement of Dagang [6]. The uplifts zones have shallow crystal basement with high magnetic value, and vise versa in Huanghua depression.

The upward continuation results at different levels $(1,2$ and $5 \mathrm{~km})$ of the gravity anomaly (Figures $4 \mathrm{a}, 4 \mathrm{~b}$ and $4 \mathrm{c}$ ) are used to compare the gravity characters of the deep crustal structure. The total horizontal derivatives of the $1 \mathrm{~km}$ upward continuation of gravity and the third order wavelet transforms are used to enhance the anomaly variation (Figures 5, 6a and 6b).

For the RTP magnetic data, the total horizontal derivative and the analytical signal modules (Figure 7a) and the tilt angle (Figure 8) are used to identify the anomaly variation pattern along the coast line. The derivative processing mainly enhanced the local magnetic anomaly variations related with igneous rocks and the fault system. The tilt angle can balance the large variations of the anomaly and react the anomaly features more clearly (Figure $7 \mathrm{~b}$ ).

The processing mainly to obtain the anomaly character of the deep

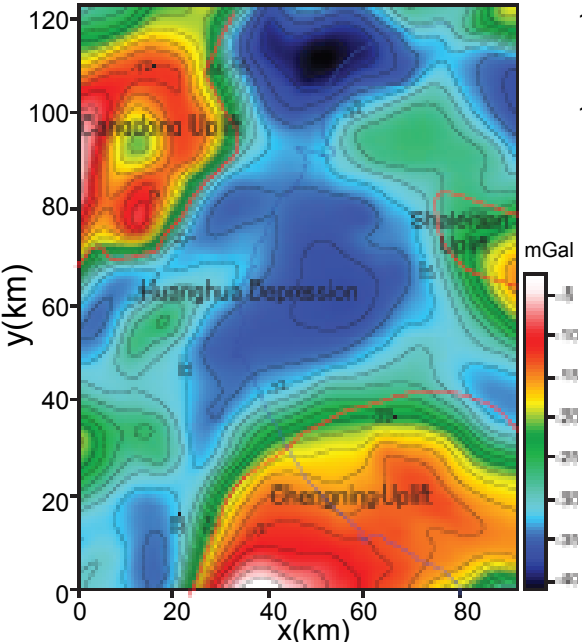

(a)

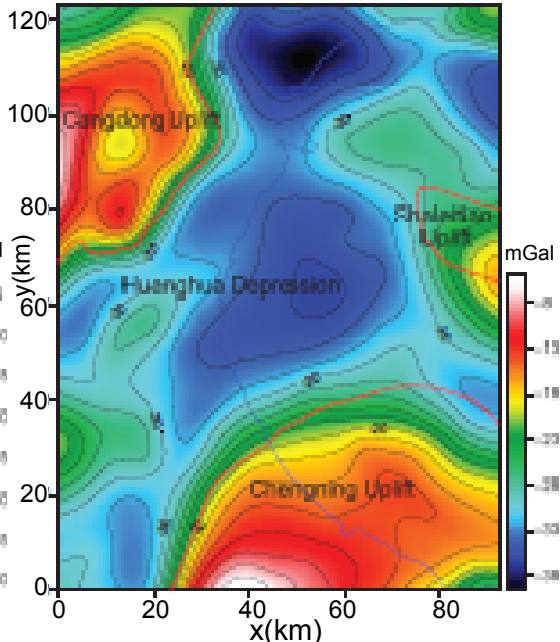

(b)

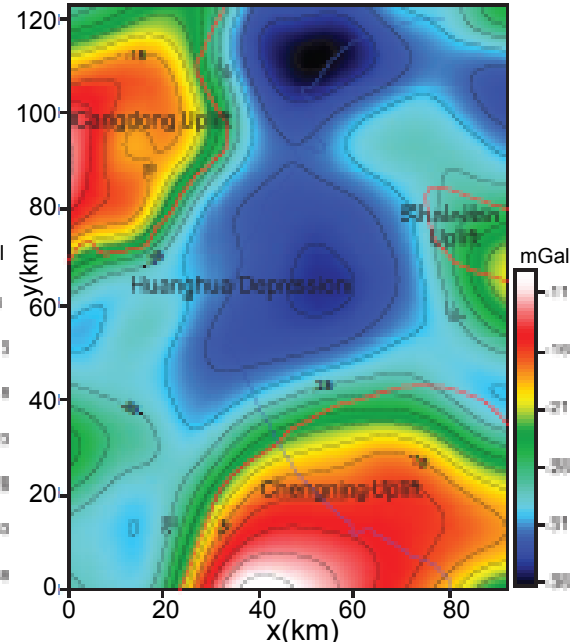

(c)

Figure 4: The upward continuations of gravity anomaly: (a) upward $1 \mathrm{~km}$; (b) upward $2 \mathrm{~km}$; (c) upward $5 \mathrm{~km}$. 
Citation: Xu Y, Hao T, Duan Q, Zhang J (2014) Deep Concealed Coastal Fault of Dagang Area, North China: Geophysical Characteristics from Potential Field Data and its Geological Implications. J Geophys Remote Sensing 3: 127. doi:10.4172/2169-0049.1000127

Page 5 of 8

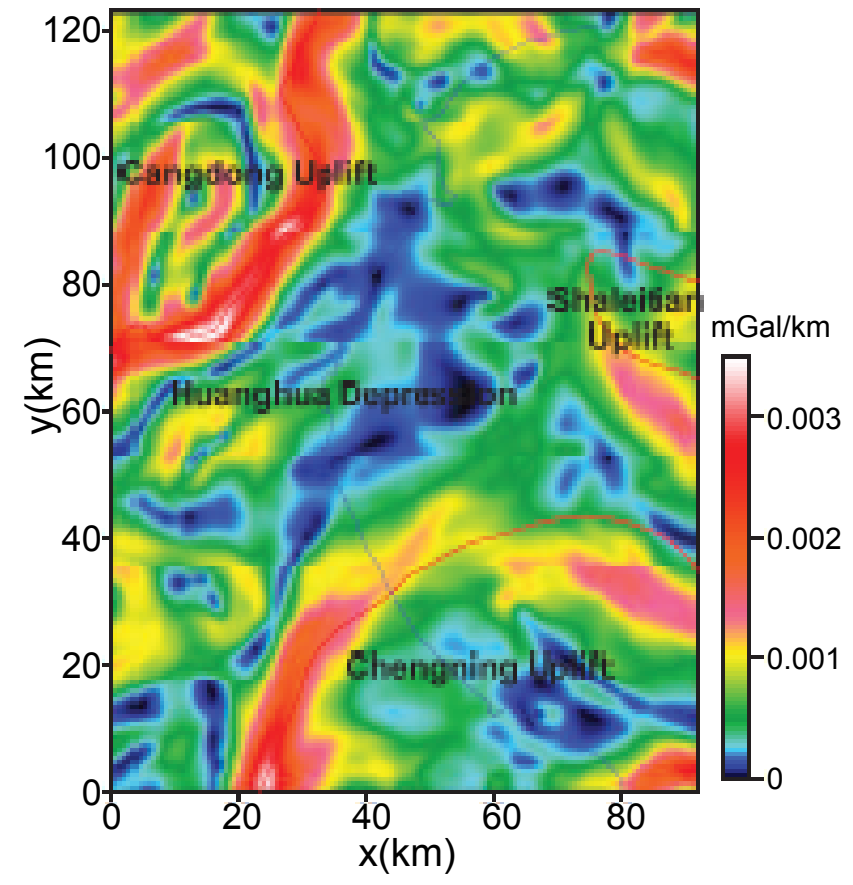

Figure 5: The total horizontal derivative of gravity anomaly with upward continuation at $1 \mathrm{~km}$. buried fault, usually by the regional anomaly character or by some local anomaly variation related with deep seated tectonic units. The processing used in this paper, the upward continuation and wavelet transform mainly focused in the regional anomaly research. On the other hand, the derivative methods were mainly used to study the anomaly variation of the shallow structures which can also reacts the deep structures.

In addition, some visualization methods, such as shade-relief image, 3D imaging etc., are used to assist the interpretation and feature extraction of the coastal fault.

\section{Geophysical Indications of the Costal Fault of Dagang Main characters of the coastal fault of Dagang}

Comparing with the typical anomaly features of fault, we can identify the coastal fault of Dagang from the gravity/RTP magnetic anomaly and their processing results. We summarized the main indications of the coastal fault of Dagang from these results.

Linear gradient belts: It's the direct evidence for the costal fault of Dagang. The gravity anomaly map shows that the linear gradient belt is about $15 \mathrm{~km}$ wide along the coastline, and the anomaly decreases about $6 \mathrm{mgal}$ from west to east. The gradient belt in the gravity upward continuation results is clearer, which reacts that the fault may extend nearly along the NS direction in the deeper crust. The regional gravity anomaly from forth and fifth wavelet decomposition [18] and the 3D PCA analysis [19] also show the gradient belt along the coastline clearly. All these regional anomalies provide the evidence for the existence of the coastal fault. It can be inferred that the costal fault extended in the deep crust along NS-NNE direction.

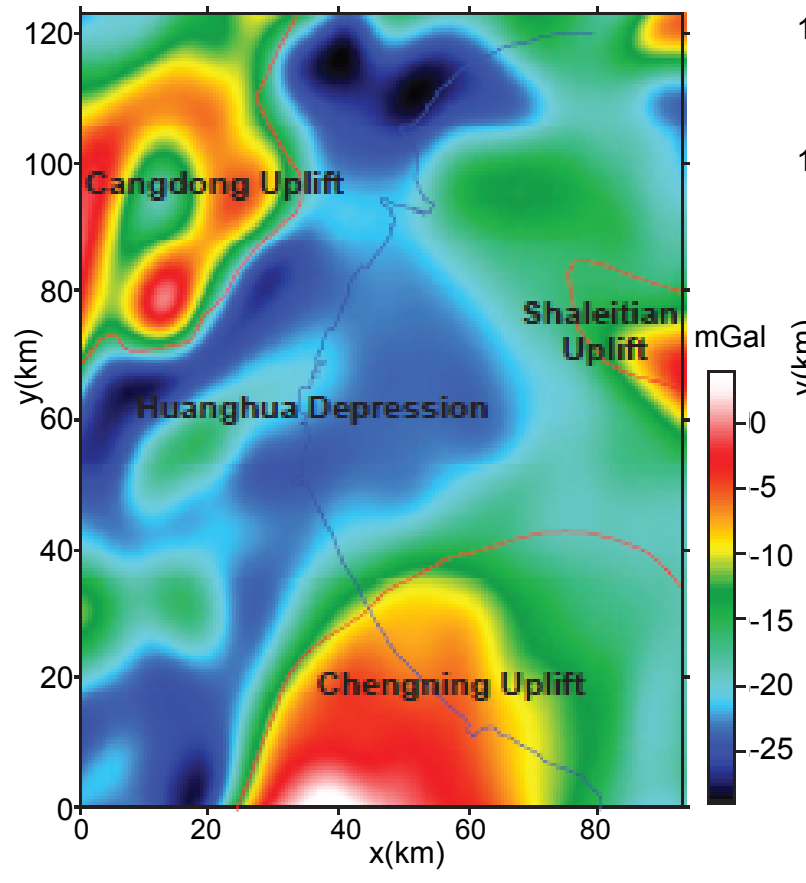

(a)

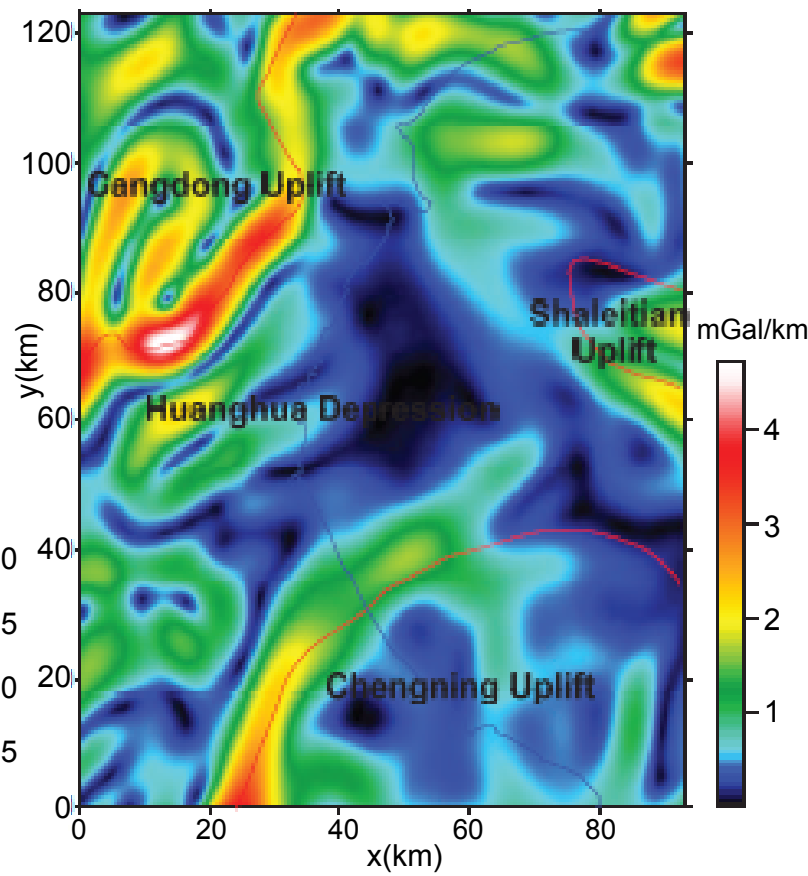

(b)

Figure 6: The third order wavelet approximation of gravity anomaly and its total horizontal derivative: (a) The third order wavelet approximation; (b) The total horizontal derivative of the third order wavelet approximation. 
Citation: Xu Y, Hao T, Duan Q, Zhang J (2014) Deep Concealed Coastal Fault of Dagang Area, North China: Geophysical Characteristics from Potential Field Data and its Geological Implications. J Geophys Remote Sensing 3: 127. doi:10.4172/2169-0049.1000127

Page 6 of 8

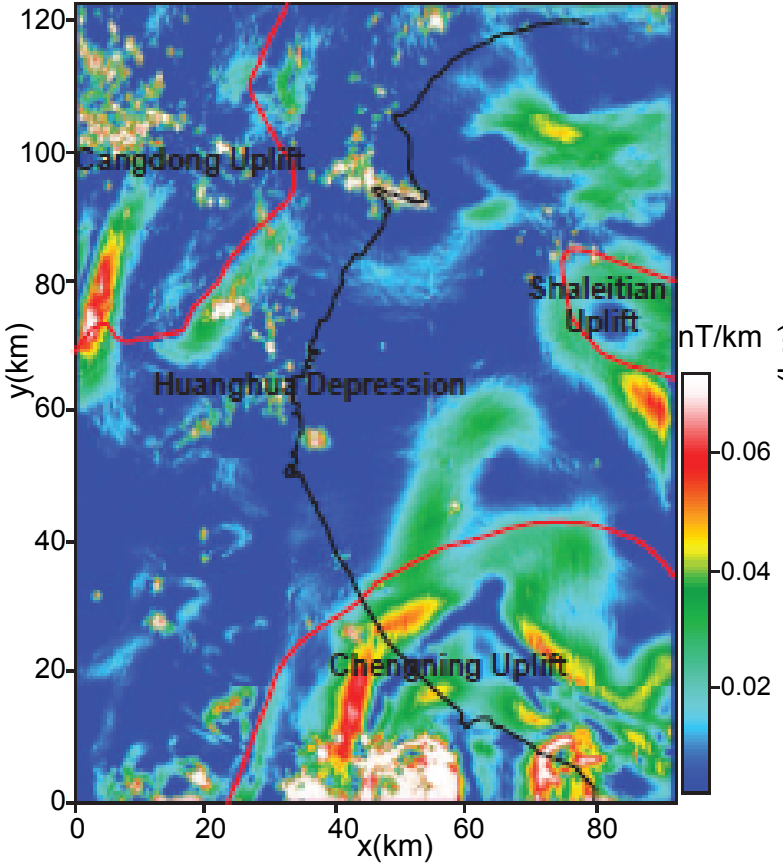

(a)

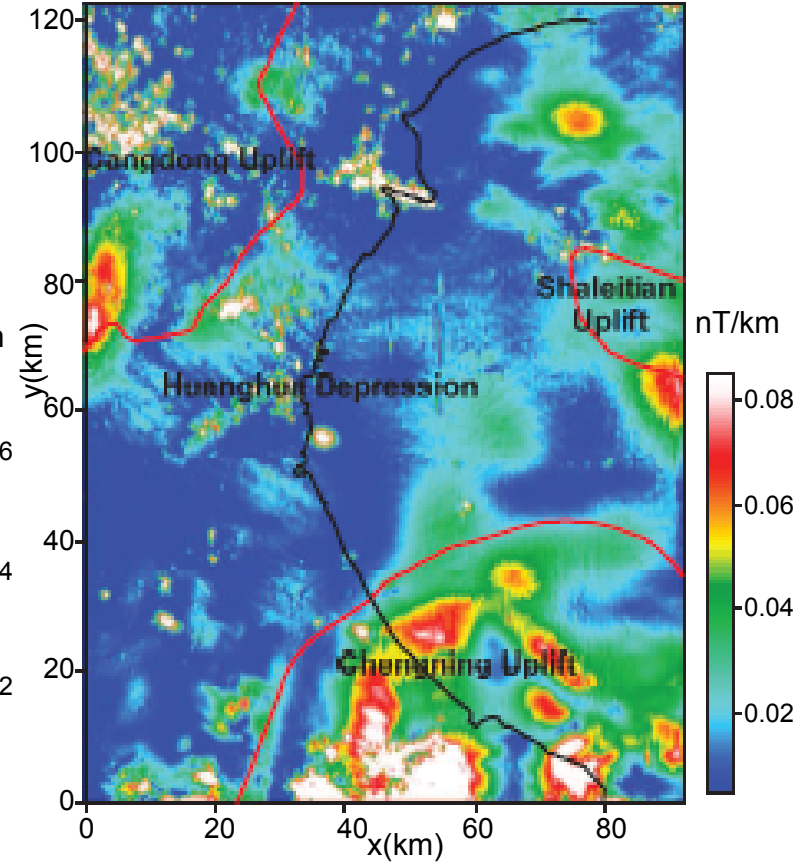

(b)

Figure 7: The total horizontal derivative and the analytical signal modules of the RTP magnetic anomaly: (a) The total horizontal derivative of the RTP magnetic anomaly; (b) The analytical signal modules of the RTP magnetic anomaly.

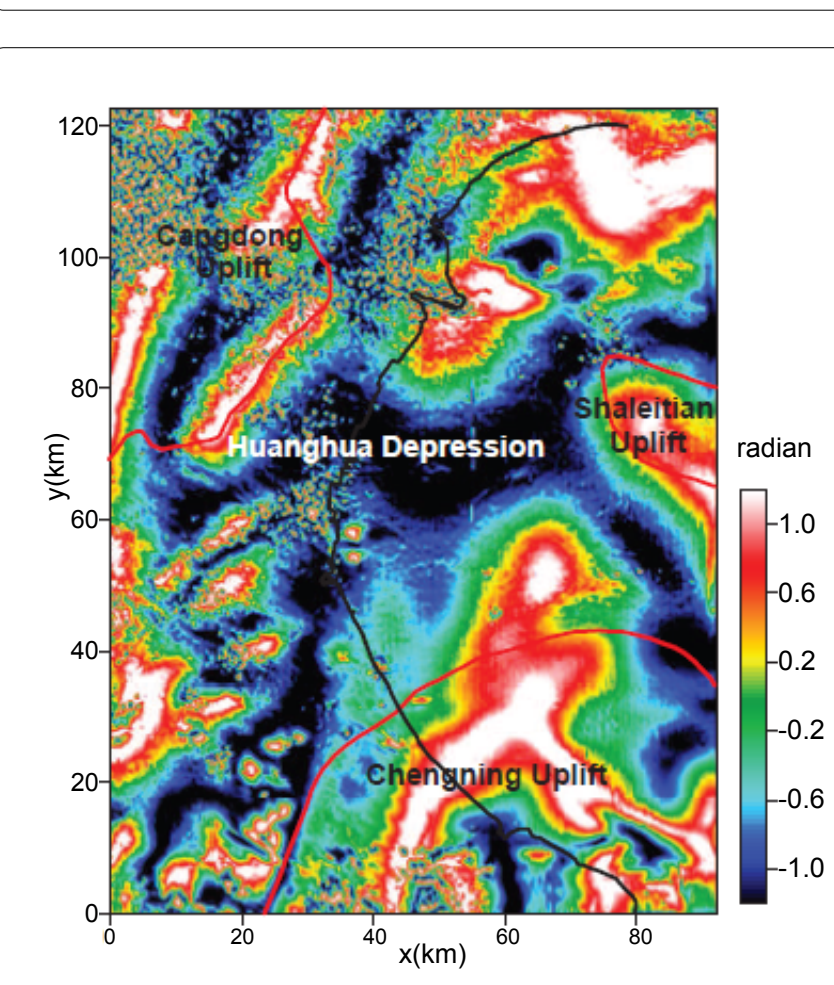

Figure 8: The tilt angle of RTP magnetic anomaly.

Transition zones: It indicates the change of the strike direction of the anomalies or their processing results across the coastal zone. From the total horizontal derivative of the gravity upward continuation and the third order wavelet transform, the dominant anomaly direction is
NE direction in the western coast of Dagang while the anomaly gently varies in the eastern coast. The tilt angle of the RTP magnetic anomaly has same transition character on the two sides of the coastline. This transition zone character is consistent with the tectonic style and Cenozoic fault system. In one word, there have two different tectonic styles and potential anomalies on the two sides of the coastal fault.

String bead-shaped magnetic anomaly: Along the coastline, there are some string bead-shaped magnetic anomalies in the RTP magnetic map. It is generally related to the distribution of igneous rocks. One interpretation is that the coastal fault is the magma upwelling channel, where the dispersive magma (igneous rocks) caused the bead-shaped magnetic anomalies. The distribution of igneous rocks in the Dagang area [4], which shows that the coastal fault is the control factor of the igneous rocks distribution. On the western coastal, there are several NE-direction igneous rock zones with bead-shaped magnetic anomaly along the Cenozoic fault system. However, there is no clear magnetic anomaly of igneous rock on the eastern coast. It consists with the former geology analysis result [2].

\section{Geology Implications and Discussions}

The coastal fault of Dagang is a tectonic transformation zone. It controls the regional structure developments together with the Zhangjiakou-Penglai fault and the Cangdong fault (Figure 1). From the tectonic evolution history [7], it experienced two stages: the Triassic to early-middle Jurassic with a NS compressive stress field and the Late Jurassic to Paleogene with a NW-SE extensional stress field. Based on the regional geology background and the tectonic evolution history, we build a basic geodynamic evolution model (Figure 9).

In this model, the Triassic (Figure 9a) to Early-Middle Jurassic is the 


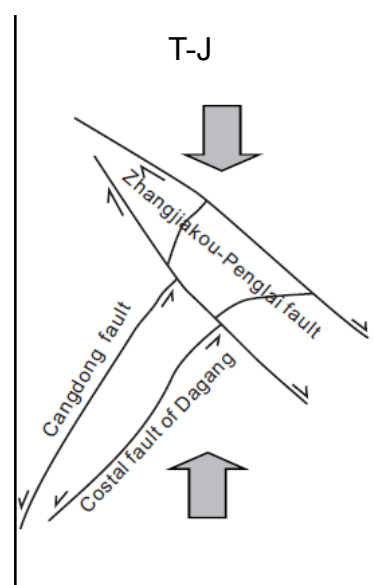

(a)

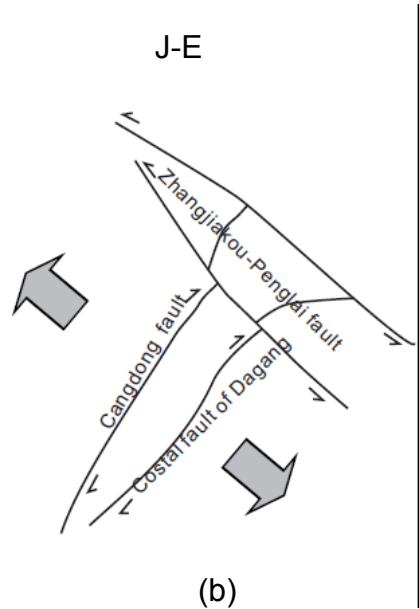

(b)
Figure 9: The geodynamic model for the Dagang area: (a) The stress field of Triassic to early-middle Jurassic; (b) The stress field of the late Jurassic to Paleogene.

main compressional deformation period of the Huanghua Depression. In this period, the activities of the Zhangjikou-Penglai fault, (ancient) Cangdong fault and the coastal fault have started and been more active. The Zhangjiakou-Penglai fault is dextral strike-slip while the (ancient) Cangdong fault and the coastal fault of Dagang is left-lateral strike-slip. The major tectonic is EW direction and it widely developed extrusion of thrust nappe structure in Huanghua Depression.

During the Late Jurassic to Paleogene (Figure 9b), with the enhanced subduction effects of the Palo-Pacific plate subducted into the Euro-Asia plate along NW direction, the Huanghua depression even the Eastern part of north China have been into the marginal Pacific tectonic development stage [20]. Affected by the subduction, the NE-NEE directional becomes the major direction of the tectonic activities. The Zhangjiakou-Penglai fault becomes left-lateral strikeslip while the Cangdong fault and the coastal fault of Dagang changes to dextral strike-slip. The Cenozoic sediment basin comes into being. Affected by the three strike-slipfaults, it formed the Qikou sag on the eastern side of the costal fault of Dagang and series sediment sag along NE direction on the western side of the costal fault.

From the dynamical evolution model, the Qikou sag, as the largest Cenozoic sag in this area, is controlled by the NW-SE extension and the NW strike-slip together, and its formation is the combined action of the extensional collapse and strike slip pull apart function. From the distribution of the igneous rocks [6] and the fault system in Figure 1, the igneous rocks mainly distributed along the coast fault of Dagang. The western part of the coast fault, the igneous rocks distributed along the sublevel faults along NE directions. It indicate that the coast fault of Dagang maybe the uplifting channel of the magma and the distribution of the igneous rocks mainly controlled by the coast fault and the sublevel NE faults at the western part.

\section{Conclusion}

The former geology studies have deduced the existence of the concealed deep fault, the coastal fault of Dagang. Here based on the gravity and magnetic data, some geophysical evidence are proposed to identify the coastal fault of Dagang. Based on the upward continuation, derivation, wavelet transform and some combined processing of the gravity and reduced to pole magnetic anomaly, the main features of the concealed costal fault of Dagang were identified as the linear gradient belt, anomaly transition zone and the bead-shaped magnetic anomaly zone.

Combined with the regional geology background and the deep fault system, a geodynamic model is proposed to explain the relationship of the coastal fault and the tectonic evolution. It has two stage tectonic evolution, the Triassic to early-middle Jurassic with the NS compressive stress field and the late Jurassic to Paleogene with the NW-SE extensional stress field. The coastal fault of Dagang changed from the left-lateral strike-slip to the dextral strike-slip during the tectonic evolution. It controlled the formation of the Qikou sag with regional deep faults. It also is the main uplifting channel of the magma and the main control factor of the igneous rocks in this region.

\section{Acknowledgment}

We thank Prof. Liu Guangding for his instruction and advice. We are grateful for the constructive comments by the anonymous reviewers. This work was supported by National Natural Science Foundation (41210005 and 41374139).

\section{References}

1. Chen Z, Chen F, Zhou J, Shi Y (1997) Characteristics of faults and paleostress analysis in north and middle area of huanghua subbasin and qikou depression. Geoscience, Journal of graduate school, China university of geosciences 11: 471-417.

2. Du X, Qi J, Lu K, Fu L (2000) Evolution and tectonic characteristics of the mesozoic basins in dagang prospect area. Petroleum Geology and Experiment 22: $125-130$.

3. Zhou L, Wu Y Xiao D, Wei A, Wang G (2000) Characteristics of the tertiary igneous rocks and investigation of their relationships with hydrocarbon in huanghua depression. Acta Petrolei Sinica 21: 29-34.

4. Xu Y, Hao T, Zhao B, Zhang L, Li Z, et al., (2011) Investigation of igneous rocks in huanghua depression, north china, from magnetic derivative methods. Journal of Geophysics and Engineering 8: 74-82.

5. Zhou L, Li S, Zhao G, Liu Z, Guo X, et al., (2004) Gravity and magnetic features of crystalline basement in the central and eastern north china craton. Progress in Geophysics 19: 91-100.

6. Hao T, Xu Y, Zhou L, Zhang L, Jiang W, et al., (2008) Integrated geophysical research on macroscopic distribution of pre-cenozoic residual basins-a case in dagang area. Chinese Journal of Geophysics 51: 332-346.

7. Wang J, Wang Y, Wan M (2011) Gravity and magnetic interpretation for oil prospecting. Petroleum Industry Press, Beijing, China.

8. Blakely RJ (1996) Potential Theory in Gravity and Magnetic Applications Cambridge University Press, London, UK.

9. Miller HG, Singh V (1994) Potential field tilt-a new concept for location of potential field sources. Journal of Applied Geophysics 32: 213-217.

10. Kirby JF (2005) Which wavelet best produces the fourier power spectrum? Computer and Geoscience 31: 846-864

11. Benson AK, Floyd AR (2000) Application of gravity and magnetic methods to assess geological hazards and natural resource potential in the Mosida hills, Utah county, Utah. Geophysics 65: 1514-1526.

12. Thurston JB, Brown RJ (1994) Automated source-edge location with a new variable pass-band horizontal-gradient operator. Geophysics 59: 546-554.

13. Cooper GRJ, Cowan DR (2008) Edge enhancement of potential-field data using normalized statistics. Edge enhancement of potential-field data using normalized statistics 73 : $\mathrm{H} 1-\mathrm{H} 4$

14. Archibald N, Gow P, Boschetti F (1998) Multiscale edge analysis of potential field data. Exploration Geophysics 30: 38-44.

15. Onyedim GC (2007) Enhancement of fault anomalies by application of steerable filters: application to aeromagnetic map of part of ifewara fault zone, southwestern Nigeria. Journal of applied sciences 7: 214-219.

16. Shi Z, Butt G (2004) New enhancement filters for geological mapping. ASEG Extended Abstracts. 
Citation: Xu Y, Hao T, Duan Q, Zhang J (2014) Deep Concealed Coastal Fault of Dagang Area, North China: Geophysical Characteristics from Potential Field Data and its Geological Implications. J Geophys Remote Sensing 3: 127. doi:10.4172/2169-0049.1000127

Page 8 of 8

17. Zhang L, Hao T, Wu J, Wang J (2005) Application of image enhancement techniques to potential field data. Applied Geophysics 2: 145-152.

18. Xu Y, Hao T, Li Z, Duan Q, Zhang L (2009) Regional gravity anomaly separation using wavelet transform and spectrum analysis. Journal of Geophysics and Engineering 6: 279-287.
19. Zhang L, Hao T, Jiang W (2009) Separation of potential field data using 3-d principal component analysis and textural analysis. Geophysical Journal International 179: 1397-1413

20. Wan T (2001) The China Tectonics. Geological Publishing House, Beijing, China. 